\title{
Consumer Demand and Intertemporal Allocations: Engel, Slutsky, and Frisch
}

\author{
Richard Blundell
}

\section{$1 \quad$ Introduction}

Individual consumers often are assumed to follow certain relatively simple budgeting rules when making expenditure decisions. For example, how much to save may be decided upon almost separately from decisions on how much to spend on food, services, and other day-to-day consumables. Of course, it is well known that such "decentralized" budgeting decisions can fit well within standard consumer theory. Indeed, the sequential nature of consumer budgeting decisions not only makes tractable the decision-making problem for the consumer but also makes it possible for the empirical microeconomist to build up a picture of consumer behaviour from a sequence of relatively straightforward estimation steps.

In his 1959 Econometrica paper "A Complete Scheme for Computing All Direct and Cross Demand Elasticities," drawing on his earlier 1932 study, Frisch saw the power of the sequential approach to analysis of consumer demand. He also developed a method for interpreting demands directly in terms of the marginal utility of money and prices when studying the analysis of allocations across groups. In particular, he considered the case in which groups were additively separable - what he termed want-independent - in which case these "Frisch" demands depended simply on own prices and marginal utility. Because marginal utility is equated across groups, the allocations between and across groups are cleverly simplified. Marginal utility is recovered up to scale from a simple within-group demand analysis - to quote Frisch (1959, p. 186), "detail

This essay was prepared for the Ragnar Frisch Centennial Symposium in Oslo, March 1995. Thanks are due to James Banks, Martin Browning, James Heckman, Arthur Lewbel, Ian Preston, Costas Meghir, and an anonymous referee for discussion of this work. This study is part of the research program of the Economic and Social Research Council (ESRC) Centre for the Microeconomic Analysis of Fiscal Policy at the Institute for Fiscal Studies. Material from the United Kingdom Family Expenditure Survey made available by the CSO through the ESRC data archive has been used by permission of the controller of Her Majesty's Stationery Office. 
about the way in which the distribution of consumption within the group depends on the price differentials within the group and the group expenditure datum." Across-group preferences are then recovered from the marginal-utility condition.

Additive separability is a highly restrictive assumption. However, it is often considered to be more reasonable in the intertemporal analysis of expected-utility maximization. Frisch did not apply these ideas to the intertemporal problem, but instead to the study of broad groups of goods. Thus it could be argued that the simplifying approach he developed has rather more appeal in the intertemporal model. Of course, with expected-utility maximization in a world in which individuals have less than perfect foresight, the estimation and interpretation of the model and its elasticities require further development and cannot rely exclusively on that presented by Frisch. However, his elasticity decomposition and the usefulness of his marginal-utility constant demands still give remarkable insight.

These important developments by Frisch took place at the same time that Gorman (1959) and Strotz (1957) were developing the ideas of separability and two-stage budgeting, with the same simplifying motivation in mind - witness the lively interchange between Strotz (1959) and Gorman. That work complemented Frisch's analysis by focusing, especially in the case of Gorman, on the grouping of prices under separability. Gorman showed that, in general, homothetic separability was a necessary and sufficient condition for two-stage budgeting. That was the requirement that a single price index be used to allocate across groups of goods. As a consequence, two-stage budgeting placed heavy restrictions on within-group preferences - in particular, the homotheticpreference assumption that restricted all within-group Engel curves to be rays through the origin. Under additive separability, that could be relaxed, but only within the generalized Gorman polar-form class. In the nonparametric analysis to be described here, those restrictions are shown to be rejected for individual-level consumer expenditure data. However, later work by Gorman (1981) showed how such preferences could be generalized in a way that would retain the simplicity of groupwise price indices while allowing for quite general Engel curves. These Engel curves, in contrast, are shown to fit the data rather well.

For intertemporal allocations, the approach of Frisch has turned out to be extremely attractive. Additive separability over time is commonly assumed and can easily be extended to account for uncertainty. Moreover, the price elasticities from the Frisch demands are identical with the good-specific intertemporal substitution elasticities of Heckman (1974) and Hall (1978). It is important to point out that where we relax the perfect-foresight assumption and allow for uncertainty, the Frisch elasticities have to be interpreted as price responses along an anticipated price path. As such, they do not necessarily correspond to the intertem- 
poral elasticities needed for policy analysis. Policy changes often are unexpected and therefore involve an unanticipated income or wealth effect.

It is easy to see that writing Frisch demands as linear or loglinear in marginal utility, though allowing estimation of intratemporal and intertemporal preferences together in one step (e.g., Browning, Deaton, and Irish, 1985), imposes unnecessarily strong restrictions on within- and between-period utilities. This has been pointed out in a number of papers, including those by Nickell (1988), Browning (1986), and Blundell, Fry, and Meghir (1989).

The sequential approach offers an attractive alternative. It is consistent with a flexible representation of consumer behaviour. It allows within-period preferences to be determined up to scale from "standard" within-period Marshallian demand analysis. The duality between these and Frisch demands means that Frisch elasticities can then be used to interpret intertemporal allocations.

This duality is most easily seen from the following relationship between the various elasticities of demand that dates back to Frisch's 1959 paper:

$$
e_{i j}^{f}=e_{i j}^{s}+\sigma \eta_{i} \eta_{j} w_{j}
$$

where $e_{i j}^{f}$ is the Frisch elasticity that holds the marginal utility of money constant, $e_{i j}^{s}$ is the Slutsky ${ }^{1}$ compensated substitution elasticity between goods $i$ and $j, \sigma$ is the intertemporal substitution elasticity for total consumption, $\eta_{i}$ is the Engel budget elasticity, and $w_{i}$ is the budget share of good $i$. It is clear from (1.1) that only one additional parameter $(\sigma)$ is needed to determine intertemporal allocations over and above the within-period elasticities $e_{i j}^{s}$ and $\eta_{i}$. That is, once $e_{i j}^{s}$ and $\eta_{i}$ are determined, knowledge of $\sigma$ completes the description of preferences over time periods and goods. I shall argue here that building up the components of (1.1) from an analysis of within-period behaviour, coupled with a separate analysis of intertemporal behaviour to recover $\sigma$, is the most effective way of allowing the data the greatest flexibility in determining the underlying preference parameters. Clearly, it would be sensible for the $\sigma$ elasticity (and other elasticities) to be allowed to vary across individuals with different demographic characteristics and different levels of overall consumption. What is surprising is that in many specifications used in empirical applications the Frisch elasticities are completely determined by within-period elasticities, leaving very little flexibility for intertemporal behaviour.

The aim of this essay, therefore, is to use the link between Frisch

${ }^{1}$ A series of letters from Slutsky to Frisch in 1926, while Slutsky was in Moscow, provided Frisch with the Slutsky decomposition of uncompensated elasticities into Engel and compensated elasticities. 
demands and Marshallian demands to provide an attractive strategy for estimating income effects, price effects, and intertemporal substitution effects in consumer demand. The Frisch approach, together with the twostage budgeting results of Gorman, are shown to provide a natural set of building blocks for analysis of consumer demand. Indeed, the first stage in estimating within-period demands is shown to break down conveniently into two steps: First, the Engel-curve relationship can be analysed for given price regimes giving the $\eta_{i}$ elasticities in (1.1). At the second step, relative-price effects and the corresponding Slutsky elasticities $e_{i j}^{s}$ in (1.1) are estimated by looking at demand shifts over time as relative prices change. It is then a simple matter to use the marginalutility-of-money relationship over time to recover the remaining intertemporal-demand parameter $\sigma$ in (1.1).

This chapter is organized to facilitate free-flowing interplay between theory and application - true to the spirit of Frisch. In the next section, the recovery of within-period demands is separated, as mentioned earlier, into a general nonparametric discussion of the Engel curve. That is followed in Section 3 by a discussion of the incorporation of relativeprice effects. These results draw on a series of detailed studies based on the individual data in the United Kingdom Family Expenditure Survey. They use new results that derive an integrable parameterisation of preferences that corresponds to the empirically coherent quadratic logarithmic Engel-curve system. In Section 4, intertemporal demands are analysed using a synthetic cohort panel drawn from the long time series of family-expenditure data available for Britain. In Section 5, some conclusions are drawn, and a comparison with some alternative approaches in the literature is made.

\section{Engel Elasticities and Nonparametric Regression}

The Engel curve has been at the centre of applied microeconomic research since the early studies of Working (1943) and Leser (1963) uncovered the stability of the expenditure-share-log-income specification for food expenditures. Frisch himself used a cross-section study of budget proportions drawn up by Leif Johansen and the Central Bureau of Statistics in Oslo and quoted results that closely accorded with the Working-Leser model. Recently, attention has focused on Engel curves that have a greater variety of curvature than is permitted by the Working-Leser form underlying the "Translog" and "Almost Ideal" models of Jorgenson, Christensen, and Lau (1975), Jorgenson and Lau (1975), and Deaton and Muellbauer (1980a,b). This reflects growing evidence from a series of empirical studies suggesting that quadratic logarithmic income terms are required for certain expenditure-share equations; see, for example, Atkinson, Gornulka, and Stern (1990), 
Bierens and Pott-Buter (1990), Hausman, Newey, and Powell (1995), Hardle and Jerison (1988), Lewbel (1991), and Blundell, Pashardes, and Weber (1993).

To analyse empirically the Engel curve, data from the United Kingdom Family Expenditure Survey (UK FES) are used. The data are split into relatively homogeneous demographic groups, and the results presented here refer to a sample of some 23,000 working-age households that are characterized by the presence of one male adult and one female adult, both being between the ages of 18 and 65 . Five broad nondurable and service groups of commodities are chosen: food, fuel, clothing, alcohol, and other nondurable nonhousing goods. ${ }^{2}$ Households are further split according to the number of children. A detailed description of these data and a comparison with other demographic groups are provided by Banks, Blundell, and Lewbel (1997). The broad results to be reported here carry over to the other main demographic groups in the population. In Section 4, when we come to analyse intertemporal behaviour by following date-of-birth cohorts over time, the demographic groups are pooled so as to get an accurate picture of the demographic changes that occur as a cohort ages.

Although our data set comes from a pooled household survey covering some 20 years, in order to focus on the shape of the Engel-curve relationship we initially consider subsamples by year and by demographic group. In this analysis, each expenditure share is defined over the logarithm of deflated income or total expenditure. Figures 5.1 and 5.2 present kernel regressions, quadratic polynomial regressions, and pointwise confidence intervals for the Engel curves for two commodity groups in a three-year period in the middle of our sample for households without children. Although from Figure 5.1 the linear formulation appears to provide a reasonable approximation for the food-share curve, for some groups (particularly alcohol and "other goods") distinct nonlinear behaviour is evident, at least in the raw data.

To construct these figures, the Gaussian kernel is used with a mean integrated-square-error optimal smoothing parameter (Hardle, 1990), but the overall shape is little affected by variations in the choice of kernel or smoothing parameter. It is interesting to focus on a comparison with the simple second-order-polynomial fit given by the dashed lines in the

${ }^{2}$ These groups were chosen primarily to be consistent with earlier studies on UK FES data. However, the results appear robust to further disaggregation of commodities (Blundell and Robin, 1997). Commodities like clothing and alcohol have significant numbers of zero values reported for expenditures in the FES diaries. In this chapter, such zeroes are treated as if they were generated through an independent infrequency-of-purchase process (Blundell and Meghir, 1997). In this case the instrumental-variable procedure can be shown to be valid. This is probably a reasonable modelling framework for clothing expenditures, but not necessarily for alcohol. 


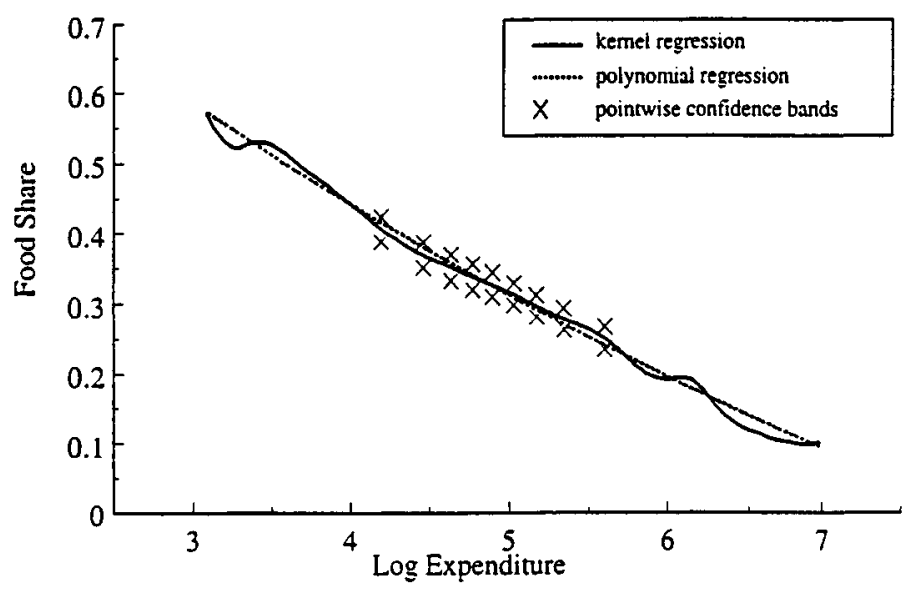

Figure 5.1. Nonparametric Engel curve: food share.

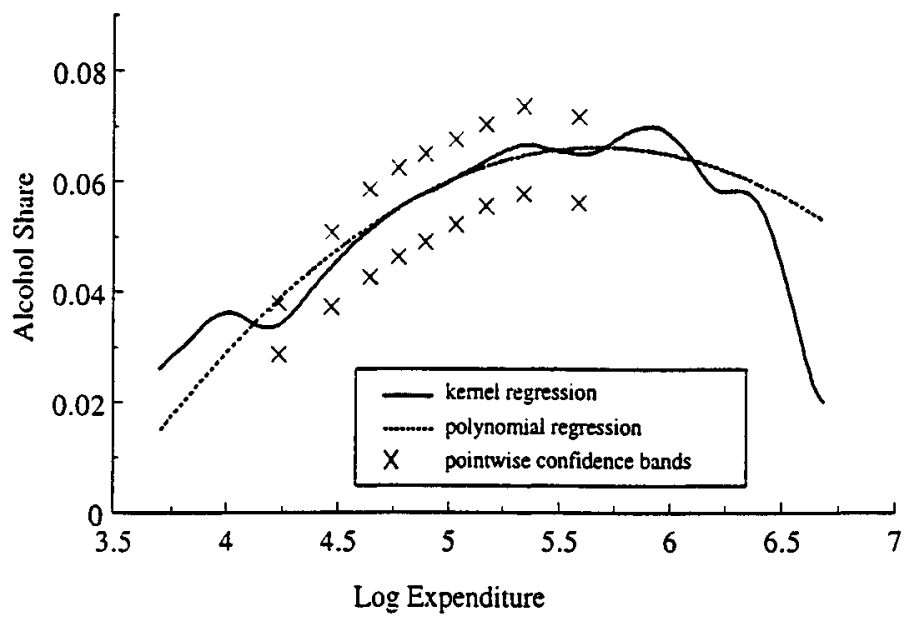

Figure 5.2. Nonparametric Engel curve: alcohol share.

figures. Some guide to the reliability of this approximation can be drawn from the pointwise confidence intervals (evaluated at the second-toninth decile points) also shown in the figures. It is only where the data are sparse and the confidence bands relatively wide that the paths diverge. For most goods it appears that expressing the budget share as a second-order polynomial in log total expenditure provides a very reliable approximation to Engel-curve behaviour.

These pictures are drawn from the study of Banks et al. (1997), where further kernel regressions are presented that indicate stability in the 


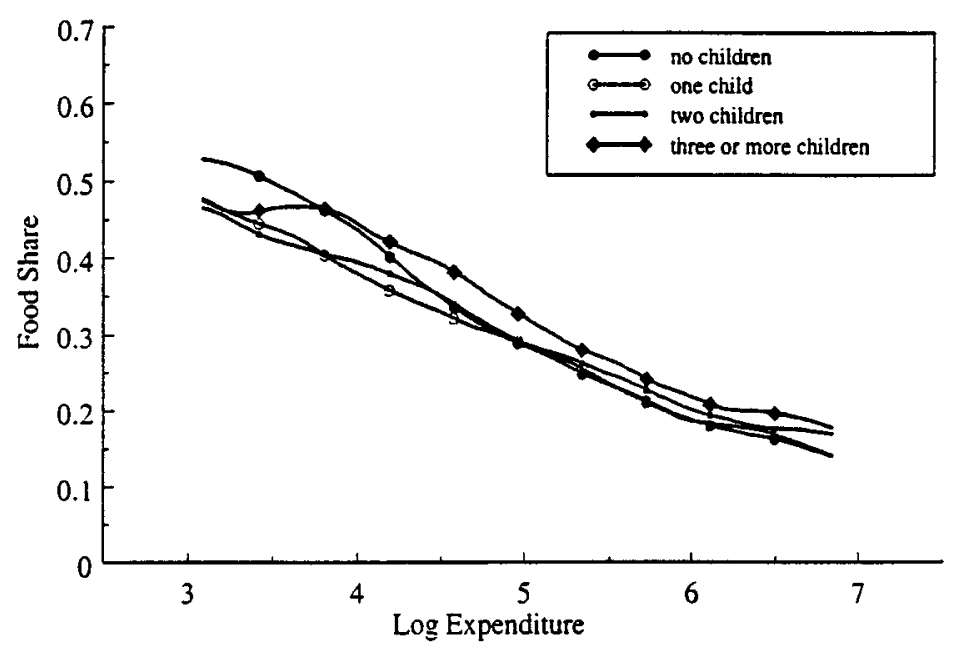

Figure 5.3. Nonparametric food share by family size: adaptive kernel.

overall patterns across time and different demographic groups. For example, Figure 5.3 plots the food-share Engel curve by household size. The linear relationship can be seen to hold across a wide range of the total-expenditure distribution. In this figure an adaptive kernel regression is used (e.g., Hardle, 1990). This allows the bandwidth to vary inversely with the density of the regressor variable so as to reduce the "wiggles" in the kernel regression line that occur where the density of log total expenditure is sparse.

These raw-data analyses should, of course, be viewed with caution, for a number of reasons. Most obviously, one would expect additional covariates. This point is largely accounted for by the selection of a homogeneous subsample. In addition, we trim any observations that lie outside three standard deviations of the mean for either log total expenditure or any of the five commodity-expenditure shares. More important are assumptions about the stochastic specification underlying the kernel regressions. The explanatory variable is the logarithm of (deflated) total expenditure on the sum of the five consumption categories. For obvious reasons this is likely to be endogenous, and it may well suffer from measurement error. The Banks, Blundell, and Lewbel study provides a detailed assessment of the extent to which the rejection of linearity can be attributed to one of these stochastic problems. In all cases the strong nonlinearity of the Engel curve is preserved, and there is found to be little evidence against the quadratic log specification.

These Engel-curve investigations suggest two distinct features of our expenditure data. For certain goods, such as food, the linear logarithmic expenditure-share model provides a robust description of behaviour. 
Second, for certain other goods, such as alcohol, the linear model needs to be supplemented by a quadratic term.

\section{$3 \quad$ Slutsky Elasticities and Marshallian Demands}

Given the exploratory analysis of the shape of the Engel-curve relationship, attention in this section turns to the derivation of a class of consumer preferences that support these results. The baseline model in which expenditure shares that are linear in log total expenditure (hereafter referred to as log income) alone has been called PIGLOG (Muellbauer, 1976), and arise from indirect utility functions that are themselves linear in log total expenditure. These preferences underlie the Almost Ideal model of Deaton and Muellbauer. Our aim here is to consider extensions of PIGLOG demands that will yield models sufficiently flexible to capture our empirical evidence on the shapes of Engel curves.

In what follows, we use $w_{i t}$ to refer to the budget share for good $i$ at observation $t, p_{t}$ to refer to the $n$-vector of prices, $z_{t}$ to refer to the $k$ vector of demographic controls, and $\ln c_{t}$ to refer to the log of total real expenditure. Working from our preferred form for the Engel curves (Banks et al., 1997), we prove the following lemma.

Lemma. Consider all demand systems that are consistent with utility maximization and have Engel curves linear in a constant, log total expenditure, and some other function of total expenditure. If these also have coefficients of rank 3 , then they are rank-3 quadratic logarithmic budgetshare systems of the form

$$
w_{i t}=\alpha_{i}\left(p_{t}, z_{t}\right)+\beta_{i}\left(p_{t}, z_{t}\right) \ln c_{t}+\psi_{i}\left(p_{t}, z_{t}\right) \ln c_{t}^{2}
$$

Quadratic models that preserve sufficient flexibility under integrability must have the specific form of (3.1). It is worth noting that an implication from Gorman (1981) is that expenditure-share models that are higher-order polynomials in $\ln c$ will always require some rank reduction in the polynomial coefficients to achieve integrability.

To construct a simple quadratic logarithmic specification that does not impose the empirically rejected proportionality (rank-2) restriction, we consider a quadratic generalization of Deaton and Muellbauer's Almost Ideal Demand System:

$$
w_{i t}=\alpha_{i}\left(z_{t}\right)+\sum \gamma_{i j} \ln p_{j t}+\beta_{i}\left(z_{t}\right) \ln c_{t}+\frac{\psi_{i}\left(z_{t}\right)}{b\left(p_{t}, z_{t}\right)} \ln c_{t}^{2}
$$

where

$$
b\left(p_{t}, z_{t}\right)=\Pi p_{j t}^{\beta_{i}\left(z_{t}\right)}
$$


and where, defining $x_{t}$ to be total nominal expenditure, log total real expenditure is given by

$$
\ln c_{t}=\ln \left(\frac{x_{t}}{a\left(p_{t}, z_{t}\right)}\right)
$$

with

$\ln a\left(p_{t}, z_{t}\right)=\alpha_{0}+\sum_{k=1}^{n} \alpha_{k}\left(z_{t}\right) \ln p_{k t}+\frac{1}{2} \sum_{k=1}^{n} \sum_{j=1}^{n} \gamma_{k j} \ln p_{k t} \ln p_{j t}$.

This has been shown (Banks et al., 1997) to correspond to an explicit indirect utility function that is a direct generalization of Deaton and Muellbuaer's LAIDS model - the QUAIDS model - given by

$$
V_{t}\left(x_{t}, p_{t}, z_{t}\right)=\frac{b\left(p_{t}, z_{t}\right)}{\ln c_{t}}+\phi\left(p_{t}, z_{t}\right)
$$

where

$$
\phi\left(p_{t}, z_{t}\right)=\Pi p_{j t}^{\psi_{i}(z t)} .
$$

To estimate this model, data are again drawn from the UK FES. The exact same procedures of sample selection and separation into demographic groups are used as in the discussion of the Engel-curve relationship in Section 2. Estimation of the model takes place over the 20-year period for the five categories of expenditures described earlier - food, fuel, clothing, alcohol, and other goods - with monthly price variations.

The system is nonlinear, and estimation follows in two stages. First, the unrestricted estimates for the nonlinear system are calculated allowing for endogeneity of the total-real-expenditure variable $\ln c$; then symmetry-restricted parameter estimates are derived using a minimumdistance procedure. In the first stage, an "iterated moment estimator" is adopted that exploits the conditional linearity of the QUAIDS model (3.2), in which budget shares are linear in unknown parameters, given the nonlinear functions $a(p)$ and $b(p)$. The consistency of this procedure and its asymptotic efficiency properties have been described by Blundell and Robin (1997). To allow for the endogeneity of $\ln c$, a Wu-Hausman augmented regression model is adopted in which a reduced-form residual for $\ln c_{t}$ is added to each budget-share equation. ${ }^{3}$ This technique preserves the adding-up and invariance properties of the demand system. The parameter $\alpha_{0}$ is chosen by grid search using the conditional log likelihood of the system as the criterion. This turns out to be a well-behaved function with a unique maximum. At the second stage, to derive the

\footnotetext{
${ }^{3}$ The log of disposable non-asset income is used as an identifying instrument.
} 
symmetry-restricted estimates, the optimal minimum-distance estimator is used; see Blundell (1988) and Browning and Meghir (1991) for a full description of this technique.

In what follows, we present the symmetry-restricted parameter estimates together with a table of compensated price and budget elasticities for the quadratic specification. The full results have been presented (Banks et al., 1997). Given the homogeneity of each of our sample splits, we choose to allow only a limited number of additional factors $[z$ in equation (3.2)] to influence preferences (i.e., age, seasonal dummies, and a time trend). Table 5.1 presents the symmetry-restricted results for the sample of married couples without children. The real-expenditure terms here correspond (after scaling) to the unconditional, nonparametric Engel curves shown previously, and one can clearly see the importance of quadratic terms in the real expenditures (particularly for clothing and alcohol), as the nonparametric analysis suggested. The coefficients on the quadratic terms in the food- and fuel-share equations have been set to zero, as suggested by the nonparametric regression analysis. These restrictions are not rejected using conventional statistical criteria in the parametric QUAIDS demand system.

In Table 5.2 we report the corresponding within-period elasticities. These elasticities are first calculated for each household individually, and a weighted average is constructed, with the weights being equal to the households' shares of the total sample expenditure for the relevant good. The corresponding Slutsky matrix has eigenvalues of $-0.2267,-0.1223$, -0.0739 , and -0.0087 , confirming the negativity prediction of consumer theory.

Given these estimates for within-period behaviour, it is possible to engage in a static analysis of tax reforms, particularly reforms to the indirect-tax system. A detailed analysis of indirect-tax reform in this model was presented by Banks, Blundell, and Lewbel (1996), where the value of estimating elasticities in terms of the accuracy of welfare measurement was also assessed.

These estimates now allow us to go on to complete the picture of consumer preferences by considering intertemporal allocations. We have now determined the Engel elasticities $\eta_{i}$ and $\eta_{i}$, as well as the Slutsky substitution elasticities $e_{i j}^{s}$. All that remains is to determine the intertemporal elasticity $\sigma$. In the next section we shall consider how to do this using the information from the repeated cross sections in the FES data.

\section{Frisch Elasticities and Intertemporal Allocations}

Our approach in deriving intertemporal allocations is based on the Hall (1978) Euler equation, which has been extensively implemented on microeconomic data, following the work of Heckman and MaCurdy (1980). Consider the behaviour of an individual or household who max- 


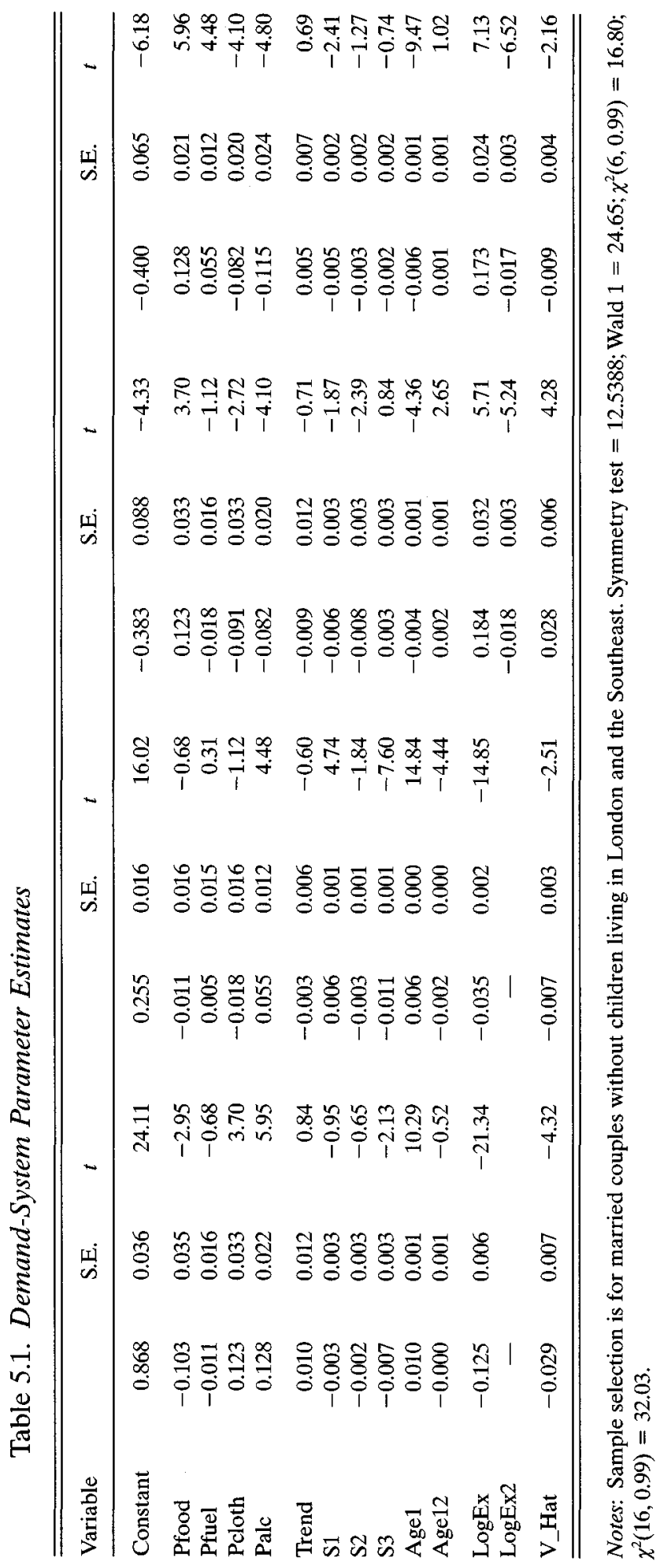


Table 5.2. Estimated Compensated Demand Elasticities

\begin{tabular}{lccrcccccccc}
\hline \hline \multicolumn{3}{c}{ Food } & \multicolumn{2}{c}{ Fuel } & \multicolumn{2}{c}{ Clothing } & \multicolumn{2}{c}{ Alcohol } & \multicolumn{2}{c}{ Budget } \\
\hline \multicolumn{2}{c}{ Compensated } \\
Food & -0.780 & $(0.15)^{a}$ & 0.108 & $(0.06)$ & 0.292 & $(0.13)$ & 0.297 & $(0.08)$ & 0.5638 & $(0.11)$ \\
Fuel & 0.471 & $(0.29)$ & -0.762 & $(0.22)$ & -0.471 & $(0.29)$ & 0.645 & $(0.19)$ & 0.4653 & $(0.20)$ \\
Clothing & 1.074 & $(0.41)$ & -0.372 & $(0.17)$ & -1.012 & $(0.42)$ & 0.063 & $(0.23)$ & 1.1634 & $(0.38)$ \\
Alcohol & 1.567 & $(0.42)$ & 0.766 & $(0.21)$ & 0.079 & $(0.41)$ & -1.692 & $(0.44)$ & 1.2594 & $(0.38)$ \\
Uncompensated & & & & & & & & & & \\
Food & -0.959 & $(0.16)$ & 0.067 & $(0.06)$ & 0.249 & $(0.13)$ & 0.267 & $(0.08)$ & & \\
Fuel & 0.319 & $(0.31)$ & -0.800 & $(0.21)$ & -0.504 & $(0.29)$ & 0.620 & $(0.19)$ & & \\
Clothing & 0.735 & $(0.44)$ & -0.448 & $(0.17)$ & -1.109 & $(0.41)$ & -0.059 & $(0.23)$ & & \\
Alcohol & 1.194 & $(0.44)$ & 0.681 & $(0.21)$ & -0.092 & $(0.40)$ & -1.764 & $(0.44)$ & & \\
\hline \hline
\end{tabular}

${ }^{a}$ Standard error.

imizes the expected sum of discounted future utilities subject to a lifetime budget constraint. ${ }^{4}$ Expected lifetime utility is given by

$$
U=E_{0} \sum_{t=1}^{T} U_{t}
$$

or, in the particular specification used later,

$$
U=E_{0} \sum_{t=1}^{T} \frac{1}{1+\rho_{t}}\left(\frac{V_{t}\left(x_{t}, p_{t}, z_{t}\right)}{\delta_{t}\left(z_{t}\right)}\right)^{1+\rho_{t}}
$$

where $V_{t}\left(x_{t}, p_{t}, z_{t}\right)$ is the within-period indirect utility derived from the QUAIDS model (3.6).

Under an assumption of perfect capital markets, period- $t$ assets $A_{t}$ are given by

$$
A_{t}=\left(1+r_{t}\right) A_{t-1}-x_{t}+y_{t}
$$

where $r_{t}$ is the period- $t$ interest rate, and $y_{t}$ is exogenous earned or transfer income in period $t$. Following the Frisch rule for the optimal allocation across additively separable groups, we find

$$
E_{t}\left(1+r_{t}\right) \lambda_{t+1}=\lambda_{t}
$$

where

$$
\lambda_{t}=\frac{\partial U_{t}}{\partial x_{t}}
$$

This is typically referred to as the Euler condition for intertemporal allocations; see Nickell (1988) or Altonji (1986), for example.

${ }^{4}$ It is easy to incorporate a bequest motive into this model, as the terminal conditions may be quite general. 
The intertemporal elasticity, or (minus) the inverse of Frisch's money flexibility, is given by

$$
\sigma_{t}=\left(\frac{x_{t}}{\lambda_{t}} \frac{\partial \lambda_{t}}{\partial x_{t}}\right)^{-1} \leq 0
$$

This describes the impact on period- $t$ consumption of a fully anticipated change in period-t prices (or real interest). For the chosen specification of preferences given earlier, this becomes

$$
\sigma_{t}=\left(\frac{\rho_{t} b_{t}-2 \phi_{t} \ln c_{t}}{b_{t}+\phi_{t} \ln c_{t}}-1\right)^{-1}
$$

With values of $\rho_{t} \leq 0, \phi_{t} \geq 0$, and $b_{t} \geq 0$, this shows a willingness to substitute that is higher for the better-off, as hypothesized by Frisch (1959).

To estimate the intertemporal parameters that govern the evolution of dynamic expenditure paths, we assume that $\rho_{t}$ is independent of demographics, which allows us to write down the intertemporal-allocation rule as

$$
\begin{aligned}
\Delta \ln c_{t}= & \rho \Delta \ln \left(\ln c_{t}\right)-(2+\rho) \ln \Delta\left(1+\phi_{t} \ln \frac{c_{t}}{b_{t}}\right) \\
& -(1+\rho) \Delta \ln \delta_{t}-(1+\rho) \Delta \ln b_{t}+r_{t-1}+\varepsilon_{t}
\end{aligned}
$$

where we have used a loglinear approximation and entered a stochastic term $\varepsilon_{t}$ to reflect the approximation error as well as the expectation error that enter after removal of the conditional expectation; see Banks, Blundell, and Preston (1994) for a detailed derivation. ${ }^{5}$ In the intertemporal equation, it is only the $\delta_{t}$ and $\rho$ parameters that are unknown. The rest are determined from the demand analysis described already; see (3.2)-(3.7). The $\delta_{t}$ parameter is specified as

$$
\Delta \ln \delta_{t}=\delta_{0}+\sum \delta_{j} \Delta z_{j t}
$$

These remaining intertemporal parameters are therefore estimated from constructed cohort data from the 20 years of FES data described earlier. This follows the methodology of Blundell, Browning, and Meghir (1994) and recovers $\delta_{t}$ and $\rho$ conditional on the Marshallian demand parameters.

Cohorts are constructed on the basis of the birth dates of heads of households. We construct 11 cohorts, each covering a five-year band, resulting in group sizes between 200 and 500 households, with a mean of 354 observations in each cohort. Of these cohorts, five are present for

${ }^{5}$ The degree of risk aversion directly enters the Euler equation for consumption growth and tilts consumption toward the future. Here it is implicitly being assumed that the degree of risk aversion is constant over time or is characterized through the demographic and labour-market variables included in the regression. 


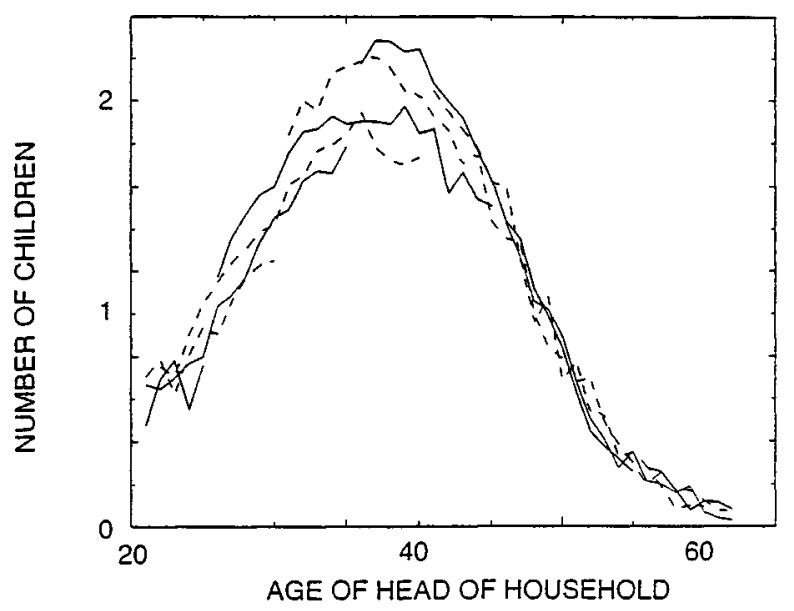

Figure 5.4. Number of children in household over the life cycle.

the full sample (i.e., 20 years), whereas young and old cohorts exist only for shorter periods at the ends of the sample. Within-period sampling errors in the construction of cohort averages lead to a resulting framework econometrically equivalent to errors-in-variables models (though with an estimatable variance-covariance structure for the measurement errors), as outlined by Deaton (1985). With sufficiently large cohort sizes, such as those here, it nevertheless becomes permissible to disregard this sampling error and treat the data as genuine panel data. After allowing for the different periods during which each cohort is observed and the loss of observations due to lagging the instrument set and taking first differences, the resulting data set comprises 133 data points. For the (individual-specific) real interest rate we take the aftertax "building-society" lending rate if the household has a mortgage, and the borrowing rate if it does not. This interest rate is then deflated by inflation - which we define as the change in the cohort average of the nondiscounted value of the individual-specific linear homogeneous price index.

Cohort-average data for number of children and total expenditure are illustrated in Figures 5.4 and 5.5. The pattern of child-bearing over the life cycle appears to be fairly stable across cohorts, with little variance over the business cycle. This contrasts somewhat with the expenditure profiles, in which the 1981/82 recession, for instance, is clearly visible. It should be noted that conditioning, as we do, on labour-market status in the estimation of both the demand system and the Euler equation may capture some of these business-cycle effects.

The orthogonality condition (4.4) is used to define a generalizedmethod-of-moments estimator (Hansen and Singleton, 1982) for the 


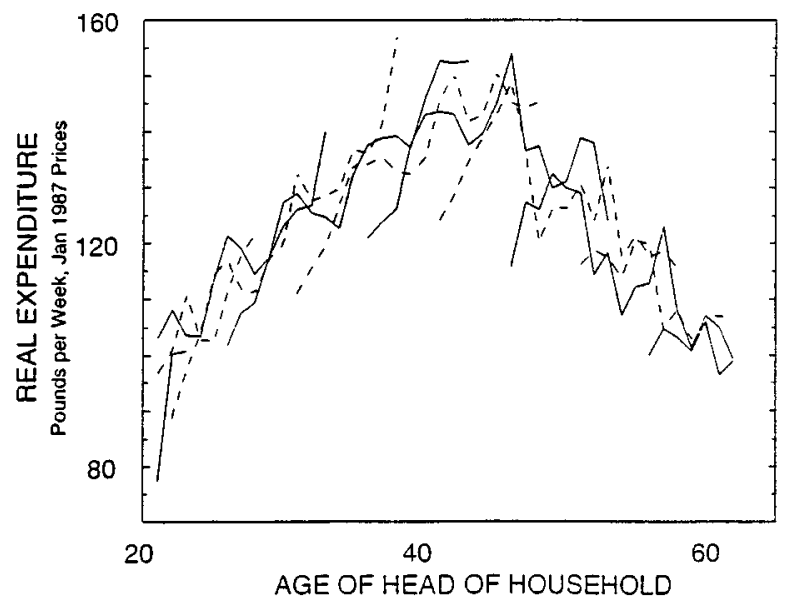

Figure 5.5. Real expenditure over the life cycle.

intertemporal relationship (4.8). The terms in the intertemporal allocation rule are nonlinear and are constructed directly by consistent aggregation in each period of individual-level data. First differences are taken at the cohort level. The specification includes demographic and labour-market-status variables that have been shown to be important in recent studies (e.g., Blundell et al., 1994; Attanasio and Weber, 1989). We also include the levels of these demographics at time $t$.

This method relies on following a cohort of individuals over time and modelling the average behaviour of the group. Thus, consider the expected value of the Euler equation, conditional on a date-of-birth cohort and on time period $t$. For consistent estimation to be possible, we need to impose certain conditions. First, because prices and interest rates vary only with time $t$, our estimation procedure (for both the demand system and the Euler equation) assumes asymptotics on both $N$ (individuals) and $T$ (time periods). Given this, the average innovations $\left\{\varepsilon_{t}\right\}$ are zero unless there are aggregate shocks affecting all members of the cohort. Moreover, any idiosyncratic random preference errors entering through the discount factor at the individual level average out at the cohort level. Thus the only sources of stochastic variation are the aggregate shocks; these are assumed to average out over our 20 years of data.

The nature of the model is such that $\left\{\varepsilon_{t}\right\}$ will be correlated with consumption, prices, and most choice variables dated $t$ (unless they are subject to relatively long decision lags). Moreover, time aggregation can induce moving-average errors, and hence $\left\{\varepsilon_{t}\right\}$ may also be correlated with (recent) past values of the decision variables and prices. Hence instrumental variables must be appropriately lagged. The instruments involve the second lags of the growth rates of income and consumption, the inter- 
Table 5.3. Intertemporal Allocations

\begin{tabular}{lllll}
\hline \hline & $(1)$ & $(2)$ & $(3)$ & $(4)$ \\
\hline Constant & 0.0435 & 0.0606 & 0.0402 & 0.0219 \\
& $(0.0117)$ & $(0.0300)$ & $(0.0095)$ & $(0.0071)$ \\
$\Delta$ Totkids & 0.2629 & 0.1685 & 0.1903 & 0.1802 \\
& $(0.1022)$ & $(0.0766)$ & $(0.0826)$ & $(0.0792)$ \\
$\Delta$ Hunemp & -1.2745 & 0.0531 & -1.4135 & \\
& $(0.6282)$ & $(0.7170)$ & $(0.4562)$ & \\
$\Delta$ WWife & 0.5734 & & & \\
& $(0.4397)$ & & & \\
$\Delta$ Mortg & -0.3612 & & & \\
& $(0.3758)$ & & & \\
TotKids & & -0.0039 & & \\
& & $(0.0177)$ & & \\
Hunemp & & -0.3721 & & \\
& & $(0.1718)$ & & \\
$\rho$ & -2.5817 & -1.3357 & -2.2264 & -1.4775 \\
& $(0.86337)$ & $(0.9731)$ & $(0.7165)$ & $(0.6475)$ \\
$\sigma$ & -0.6511 & -0.7771 & -0.6827 & -0.7604 \\
& $(0.1716)$ & $(0.1914)$ & $(0.1445)$ & $(0.1309)$ \\
$\delta_{1}$ & 0.1662 & 0.5019 & 0.1551 & 0.3774 \\
& $(0.0776)$ & $(1.3387)$ & $(0.0804)$ & $(0.4458)$ \\
Sargan & 18.4270 & 24.0889 & 24.7710 & 37.3044 \\
d.f. & 16 & 16 & 18 & 19 \\
S.E. of eq. & 0.0070 & 0.0042 & 0.0059 & 0.0054 \\
\hline \hline
\end{tabular}

Notes: Standard errors are given in parentheses. Variables are levels at time $t$, or first differences (indicated by $\Delta$ ). Hunemp is a dummy for head of household unemployed; WWife is a dummy for working female; Mortg is a dummy for presence of a mortgage; Totkids is the total number of children of all ages. Instruments are number of children in each of four age groups, age of head, age of spouse, working-male and working-female dummies, lending and borrowing interest rates, tenure and region dummies; all instruments are dated $t-2 . \sigma$ is calculated at the mean $\ln c_{t}$ for the sample of 4.76714 (at January 1987 prices).

actions of the latter with characteristics, and the characteristics themselves. The latter are either dated $t-2$ (labour-market status) or dated $t$ (all other demographic variables). Consistency requires the grouped instruments to be orthogonal to the grouped error term over time. This will be true if each member of the cohort has in his information set the average cohort values of the variables we use as instruments. If the individuals' information sets contain only values relating to themselves, then this orthogonality condition will not be satisfied, and cohort aggregation will not lead to consistent parameter estimates, despite our exact aggregation procedure (Pischke, 1991). 
Table 5.3 reports a sequence of alternative models taken from the Banks et al. (1994) study, with the first two columns containing the most general specifications. Column 3 presents a more parsimonious representation of these results, which, as can be seen, would not be rejected by the data, and also allows us to focus on the effects of children on the change in $\delta_{t}$. This retains the influence of head unemployed, and column 4 shows that the $\rho$ parameter in particular is sensitive to the exclusion of this variable, although the overall impact on the intertemporal elasticity $\sigma$ is negligible. This intertemporal substitution elasticity is evaluated at the sample mean level.

The presence of a term like $\delta_{t}$ is attractive because we may wish to allow for the possibility that the presence of children in certain periods may make spending in those periods more or less appealing independently of the impact of children on the within-period composition of spending. Such an effect cannot be picked up by traditional Marshallian demand analysis. The term $\rho$ is included to allow us to estimate the degree to which families are prepared to substitute expenditure away from the relatively expensive periods.

The results of Table 5.3 complete the analysis of household expenditure patterns. Having determined $\sigma$ - which will vary across households depending on their demographic, labour-supply, and consumption patterns - we can return to the Frisch elasticity decomposition (1.1) described in the Introduction. The estimated Engel, Slutsky, and Frisch elasticities provide a complete picture of substitution across time and across goods. Naturally, the interpretation of estimated elasticities depends on the theoretical assumptions required to identify them as parameters of interest. Such assumptions are fairly innocuous for Engel elasticities, but require optimizing agents behaving according to the predictions of demand theory. For the Slutsky elasticities, this requires weak separability between these within-period decisions and decisions over other goods that do not enter the modelled demand equations. For the intertemporal elasticities, we also require additive separability over time and the rational use of information, as given by the stochastic Euler or marginal-utility condition (4.4). Lying behind this first-order condition is the assumption of perfect credit markets, which implies that the real interest rate is independent of the amount of borrowing or saving that a consumer does in transferring resources optimally across time so as to satisfy the marginal-utility condition.

\section{$5 \quad$ Summary and Conclusions}

The approach in this chapter has been to exploit the two-stage budgeting properties of an intertemporally separable model under uncertainty to simplify the estimation of consumer preferences. That has enabled us first to identify the characteristics of within-period behaviour from a detailed 
microlevel demand analysis on pooled cross-section data; and then to estimate the remaining parameters that identify intertemporal behaviour using a panel of cohort data constructed from our repeated cross sections. The sequential approach has exactly mirrored the Frisch decomposition of elasticities into Engel effects, Slutsky terms, and intergroup allocations. In contrast to the work of Frisch, however, the intergroup allocations in this study are the allocations of consumption over time under uncertainty.

The advantage of the approach followed in this chapter can be seen from the invariance of the resulting within-period preference estimates to assumptions concerning the degree of intertemporal substitution. Indeed, the Engel-curve relationship was examined using nonparametric regression and using the very minimum of economic assumptions suggesting a quadratic Engel-curve relationship between budget shares and $\log$ total expenditure. Within-period preferences were estimated using a QUAIDS demand system consistent with the finding of quadratic Engel curves. These estimates, based on a long time series of repeated cross sections, were found to be both data- and theory-coherent. The full specification of life-cycle preferences was then completed with an intertemporal analysis of consumption growth following date-of-birth cohorts through their life-cycles. Intertemporal allocations were found to depend on labour-market variables and the numbers of children, as well as the consumption level itself.

\section{References}

Altonji, J. G. (1986). Intertemporal substitution in labour supply: evidence from micro-data. Journal of Political Economy 94:S176-215.

Atkinson, A. B., Gomulka, J., and Stern, N. H. (1990). Spending on alcohol: evidence from the Family Expenditure Survey 1970-1983. Economic Journal 100:808-27.

Attanasio, O. P., and Weber, G. (1989). Intertemporal substitution, risk aversion and the Euler equation for consumption. Economic Journal (Suppl.) 99:59-73.

(1993). Consumption growth, the interest rate and aggregation. Review of Economic Studies 60:631-50.

Banks, J., Blundell, R. W., and Lewbel, A. (1996). Tax reform and welfare measurement: Do we need demand system estimation? Economic Journal 106:1227-42.

(1997). Quadratic Engel curves and consumer demand. Review of Economics and Statistics 79:527-39.

Banks, J., Blundell, R. W., and Preston, I. (1994). Life-cycle expenditure allocations and the consumption costs of children. European Economic Review 38:1391-410.

Bierens, H. J., and Pott-Buter, H. A. (1990). Specification of household Engel curves by nonparametric regression. Econometric Reviews 9:123-84. 
Blundell, R. W. (1988). Consumer behaviour: theory and empirical evidence. Economic Journal 98:16-65.

Blundell, R. W., Browning, M. J., and Meghir, C. (1994). Consumer demand and the life-cycle allocation of household expenditures. Review of Economic Studies 61:57-80.

Blundell, R. W., Fry, V., and Meghir, C. (1989). $\lambda$-constant and alternative empirical models of life-cycle behaviour under uncertainty. In: Advances in Microeconometrics, ed. J.-J. Laffont et al. Oxford: Blackwell.

Blundell, R. W., and Meghir, C. (1997). Bivariate alternatives to the Tobit model. Journal of Econometrics 34:179-200.

Blundell, R. W., Pashardes, P., and Weber, G. (1993). What do we learn about consumer demand patterns from micro data? American Economic Review 83:570-97.

Blundell, R. W., and Robin, J.-M. (1997). Estimation in large disaggregated demand systems: an iterated linear least squares estimator. UCL working paper 97-5.

Blundell, R., and Walker, I. (1986). A life-cycle consistent empirical model of family labour supply using cross-section data. Review of Economic Studies 53:539-58.

Browning, M. J. (1986). The costs of using Frisch demand functions that are additive in the marginal utility of expenditure. Economics Letters 21:205-9.

Browning, M. J., Deaton, A. S., and Irish, M. (1985). A profitable approach to labour supply and commodity demands over the life-cycle. Econometrica 53:503-44.

Browning, M., and Meghir, C. (1991). The effects of male and female labor supply on commodity demands. Econometrica 59:925-51.

Chamberlain, G. (1984). Panel data. In: Handbook of Econometrics, ed. Z. Griliches. Amsterdam: North Holland.

Deaton, A. S. (1985). Panel data from time series of cross sections. Journal of Econometrics 30:109-26.

Deaton, A. S., and Muellbauer, J. (1980a). An almost ideal demand system. American Economic Review 70:312-26.

(1980b). Economics and Consumer Behaviour. Cambridge University Press.

Duncan, A. S., and Jones, A. S. (1992). NP-REG: an interactive package for kernel density estimation and non-parametric regression. IFS working paper W92/07.

Frisch, R. (1932). New Methods of Measuring Marginal Utility. Tübingen: Mohr. (1959). A complete scheme for computing all direct and cross demand elasticities in a model with many sectors. Econometrica 27:177-96.

Gorman, W. M. (1959). Separable utility and aggregation. Econometrica 27:469-81.

(1981). Some Engel curves. In: Essays in the Theory and Measurement of Consumer Behaviour, ed. A. S. Deaton. Cambridge University Press.

Hall, R. E. (1978). Stochastic implications of the life-cycle permanent income hypothesis: theory and evidence. Journal of Political Economy 86:971-88.

Hansen, L. P., and Singleton, K. J. (1982). Generalised instrumental variable estimation of non-linear rational expectations models. Econometrica 50:1269-86. 
Hardle, W. (1990). Applied Nonparametric Regression. Cambridge University Press.

Hardle, W., and Jerison, M. (1988). The evolution of Engel curves over time. Discussion paper no. A-178, SFB 303, University of Bonn.

Hausman, J. A., Newey, W. K., Ichimura, H., and Powell, J. L. (1991). Identification and estimation of polynomial errors in variables models. Journal of Econometrics 50:273-96:

Hausman, J. A., Newey, W. K., and Powell, J. L. (1995). Nonlinear errors in variables: estimation of some Engel curves. Journal of Econometrics 65:205-34.

Heckman, J. J. (1974). Life-cycle consumption and labour supply: an explanation of the relationship between income and consumption over the life-cycle. American Economic Review 64:188-94.

Heckman, J. J., and MaCurdy, T. E. (1980). A life-cycle model of female labour supply. Review of Economic Studies 47:47-74.

Jorgenson, D. W., Christensen, L. R., and Lau, L. J. (1975). Transcendental logarithmic utility functions. American Economic Review 65:367-83.

Jorgenson, D. W., and Lau, L. J. (1975). The structure of consumer preferences. Annals of Social and Economic Measurement 4:49-101.

(1979). The integrability of consumer demand functions. European Economic Review 12:115-47.

Jorgenson, D. W., Lau, L. J., and Stoker, T. M. (1980). Welfare comparison and exact aggregation. American Economic Review 70:268-72.

Leser, C. (1963). Forms for Engel curves. Econometrica 31:694-703.

Lewbel, A. (1991). The rank of demand systems: theory and nonparametric estimation. Econometrica 59:711-30.

MaCurdy, T. E. (1983). A simple scheme for estimating an intertemporal model of labour supply and consumption in the presence of taxes and uncertainty. International Economic Review 24:265-89.

Muellbauer, J. (1976). Community preferences and the representative consumer. Econometrica 94:979-1000.

Nickell, S. J. (1988). The short-run behaviour of labour supply. In: Advances in Econometrics: Fifth World Congress, vol. 2, ed. T. F. Bewley. Cambridge University Press.

Pischke, J.-S. (1991). Individual income, incomplete information, and aggregate consumption. Discussion paper no. 91-07, Zentrum für Europaische Wirtschaftsforschung, Mannheim.

Strotz, R. H. (1957). The empirical implications of the utility tree. Econometrica 25:269-80.

(1959). The utility tree - a correction and further appraisal. Econometrica $27: 482-8$.

White, H. (1980). A heteroskedasticity-consistent covariance matrix estimator and a direct test of heteroskedasticity. Econometrica 48:817-38.

Working, H. (1943). Statistical laws and family expenditure. Journal of the American Statistical Association 38:43-56. 